\title{
Factors Associated With Work-Life Balance of Working Fathers Involved in Small Business Enterprises: Evidence from Kathmandu Nepal
}

\section{Rocky Mani Shakya ${ }^{I}$, Niranjan Devkota ${ }^{1 *} \oplus$, Udaya Raj Paudel ${ }^{1} \oplus$, Seeprata Parajuli ${ }^{1}(0$}

Quest International College, Pokhara University, Lalitpur, Nepal

* Corresponding Author (niranjan@quest.edu.np)

Received: 12 September, 2021

Revised: 11 October, 2021

Accepted: 20 December, 2021

Published: 25 December, 2021

How to cite this paper:

Shakya, R.M., Devkota, N., Paudel, U.R., \& Parajuli, S. (2021). Factors associated with work-life balance of working fathers involved in small business enterprises: Evidence from Kathmandu Nepal. Quest Journal of Management and Social Sciences, 3(2), pp. 193-203.

\section{Abstract}

Background: Work-life balance (WLB) can be considered as the systematic management of three important components like work-life conflict, work-life interference and work-life convergence.

Objective: This study tries to examine the work-life balance of the working fathers involved in small business enterprises in Kathmandu valley.

Method: Both descriptive and inferential analysis is used in the study which showed various results. The study adopted the descriptive approach. Respondents were sampled from working fathers in small business enterprises in Kathmandu valley. Non probability sampling technique was used to select 405 respondents. The questionnaire was used for data collection. Descriptive as well as inferential statistics were used for data analysis.

Result: The study found that age, education level, business trainings and income level has positive significant relationship with work-life balance. The finding of this study shows that satisfaction and motivation towards working fathers is important factors for balancing the work-life and family life.

Conclusion and Recommendation: The paper recommends that there should be inclusive climate in the workplace and policies supporting work-life balance should be forwarded.

Paper Types: Research Paper

Key Words: Work-Life Balance, Working Fathers, Small Business Enterprises, Kathmandu Valley, Descriptive Analysis, Inferential Analysis

JEL Classification: A39, J29, J60, J61, J81, and J83.

Copyright (C) 2021 by authors and Quest Journal of Management and Social Sciences.

This work is licensed under a Creative Commons Attribution-Non Commercial-No Derivatives 4.0 International License. 


\section{Introduction}

Some decades ago, men were considered as the family breadwinners and whereas women were considered as the homemakers. During the early part of the 20th century the campaign to reduce working hours continued through a series of pioneering studies which demonstrated the relationship between time spent at work and the level of output was a complex one. Likewise, Naithani (2010) discussed that during the second half of 20th century, with work demands increasingly encroaching on family and personal time at a faster pace, employers acknowledged the need of work-life balance programs in order to facilitate employees maintain a healthy balance between the conflicting demands of their work life and personal life.

Work-life balance is the systematic management of three important components like work-life conflict, work-life interference and work-life convergence (Quesenberry \& Trauth, 2005). Hogarth and Bosworth (2009) explained that the history of work-life balance begins in the latter half of the 19th century when reformers successfully campaigned against the long factory hours and they were able to demonstrate that reductions in working hours had no significant impact upon levels of output. Government policies on working hours and parental leave and concludes that western countries have fewer working hours and more generous parental leave in comparison to their counterparts in Asia (Chandra, 2012).

Work-life imbalance can impair an organizational effectiveness through absenteeism and high rates of turnover which may arise as a result of family obligations that is associated with stress and mental health (Maslach et al., 2001). Poor work-life balance has various negative impacts on the workplace viz. performance reduction, job satisfaction as well as higher level of conflict. It is necessary to keep in mind that stress related absenteeism and mental health problems in the workplace are on the rising trend (Ravalier et al., 2016). Pathak (2015) has mentioned that due to challenges in personal life like caring of an aging parent and coping with marital problems, focusing on job becomes complex; whether the problem is too focus on work or not, the work life and personal life feel out of balance, the ultimate result being the lack of personal and work achievement. Researchers have suggested that work-life balance is an overarching bi-dimensional concept that is operating in two different directions where work interferes with family and reversely family to work where family interferes with work. Of these, work-to-family seems to be experienced more than family-to-work (Carlson et al., 2000; Tang and Cousins, 2005) and has received more attention (Geurts and Demerouti, 2003).

In Nepalese context, Gnawali (2017) states that working fathers in the context of Nepal actually think that balancing the work-life as well as family life is quiet a difficult task due to the lack of allocation of proper time to the family. In the present context of Nepal, work life balance has always been an important issue because of its significant influence over career choice, time management, stress management as well as other various important aspects of day to day life of human beings (Pathak, 2015). This study tries to analyze factors associated with work-life balance of fathers associated in small business enterprises. After completion of this study it is assumed that the findings will be helpful to organizations to prepare strategy that would help in maintaining work-life balance, fathers would also take some insight from the study and both working fathers and organizations could make strategies accordingly to take corrective actions towards maintenance of work-life balance.

This study further includes review of literature in second section, followed by research methods in third. Likewise, data analysis and result is covered in fourth section finally last section concludes the study with recommendation.

\section{Review of Literature}

It is a global phenomenon which has always been an important issue because of its significant influence towards job satisfaction, time management, stress management and other significant aspects of day to 
day life of human beings (Pathak, 2015). In the present context most of the companies are becoming aware of the significance of work-life balance and hence assumed it as an important tool to attract as well as retain the talents and facilitate sustainable human resources Hossen et al. (2018). In the recent years the studies on work and family role enhancement seem to be growing rapidly (Grzywacz, 2000). Work and family role interference recommends that responsibilities in work and family compete with each other regarding physical energy, limited time and psychological resources which directly lead to negative outcomes (Greenhaus \& Beutell, 1985). The work and family influence each other in both a positive as well as negative way. For example; time, attitudes, stress, tasks, emotions, and behavior spillover among work and family (Gnawali, 2017).

Hill et al. (2001) described that work-life balance is all about how an individual simultaneously balances the temporal, emotional, and behavioral demands of paid and non-paid work activities. Adams et al. (1996) mentioned that the relationship between work and family can directly effect on job and life satisfaction. Pocock (2005) believed that work-life balance requires still a broader definition due of its linkage to various parties' viz. individuals, enterprises and society. Mcenhill and Steadman (2015) reported that around 43 percent of the employees are failing to achieve a satisfactory balance between their work and personal life. This number has remained high for many years showing that companies are not succeeding in improving the work-life balance situation for their workforce. Out of many one of the most significant negative impacts of a lack of satisfactory work-life balance is stress which may cause a huge loss in organizational productivity and performance reduction.

Karambayya and Reilly (1992) have observed an attitudes and actions in restructuring the work for family. From the data set consisting of survey responses from both members of 39 dual earner couples, work and family involvement was used to predict job satisfaction and marital satisfaction. In addition, the responses to seven open ended questions showed qualitative data reflecting what specific types of work restructuring arrangements were most popular and the reasons for work restructuring. Because our qualitative data is being generated through written responses to survey questions instead of interviews, researchers were not able to search for the nuances which in-depth interview transcriptions can provide. However, from the analysis, Smithson and Stokoe (2005) have concluded that changing the terminology of equality does not itself contribute significantly in advancing gender equality. Several scholars have studied work-life balance including Borgh et al. (2018) where a cross sectional study design has difficulty in confirming temporality between hypothesized predictor and outcome variables which impeded the possibility to draw any conclusions about the causality in Sweden. Similarly, Mills and Grotto (2017) have explored the intersection of the work-life, leadership and gender domains where research is still lacking concerning gender differences in the work-life in USA.

Hobson and Fahlen (2009) examined the competing scenario for European working fathers by applying the capabilities and agency framework to work family balance. The survey was conducted using semi-structured interviews of fifty men and fifty women in order to create cross currents for fathers: the promotion of work-family balance (WFB) and more involved fathering versus work-focused competitiveness and productivity goals in globalized economies. Specifically, Albertsen et al. (2008) observed scientific evidence where long work hours are negatively associated with work life balance and part-time work is positively associated with work life balance. Rusten et al. (2019) studied the importance of going beyond maternal factors and considering the broader family unit in order to create a fuller picture of the factors that have the potential to influence child development. Salzmann-Erikson (2017) studied to enhance gender equality, particularly related to parental leave, have been established in Sweden. Similarly, developing a conceptual framework with a capabilities and agency approach for analyzing the work life balance which is applied in Hungary and Sweden, having various working time regimes and gender equality discourses and norms (Hobson et al., 2011). 
Williams et al. (2016) observed the work-life integration where research on the work family interface began in the 1960s and has grown rapidly then. More importantly, the work devotion schema underwrites valued class and gender identities. Advocating change in the way work is done and life is lived meets resistance due to these cherished identities at risk. Resistance to these identity threats keeps current workplace norms in place which shows that current practices are not economically efficient. More specifically Ritvo (1971) has mentioned that the ego ideal is very useful in understanding the problems of homosexuality that occur in late adolescence in connection with the approach to the new object and with taking steps in the realistic world which have a crucial quality for the individual in relation to his self-esteem. One problem with the current literature is that it does not examine the differential meaning of work either at home or at the employing organization being applied both for men and women (Zedeck \& Mosier, 1990). Likewise, Hall (1990) explained that they have been operating under the assumption that as organizations and society change, they will find ways for career women to have it all such as lovely homes, executive success, loving spouses, wonderful children and others as well. A major problem lies in the fact that they lack a set of conceptual tools by which they can integrate sociological, maturational, psychological and historical perspectives on the life cycle (Neugarten \& Datan, 1973).

\section{Research Methods}

\section{Study Area}

This study focuses on mainly the working fathers who are involved in small business enterprises with at least one child. Kathmandu valley, Province no. 3, Nepal is chosen as study area. Kathmandu Valley comprises of three districts namely; Kathmandu, Lalitpur, and Bhaktapur (Ishtiaque et al., 2017; Adhikari et al., 2021) which cover an area of 899 square kilometers, whereas the area of the Valley as a whole is 665 square kilometers. Being the capital city of Nepal and one of the only regions which accumulates highest concentration of population, conducting a research on work-life balance of working fathers involved in small business enterprises in Kathmandu gives better and more factual results. The figure 1 shown below represents the study area of this research.

Figure 1: Study Area

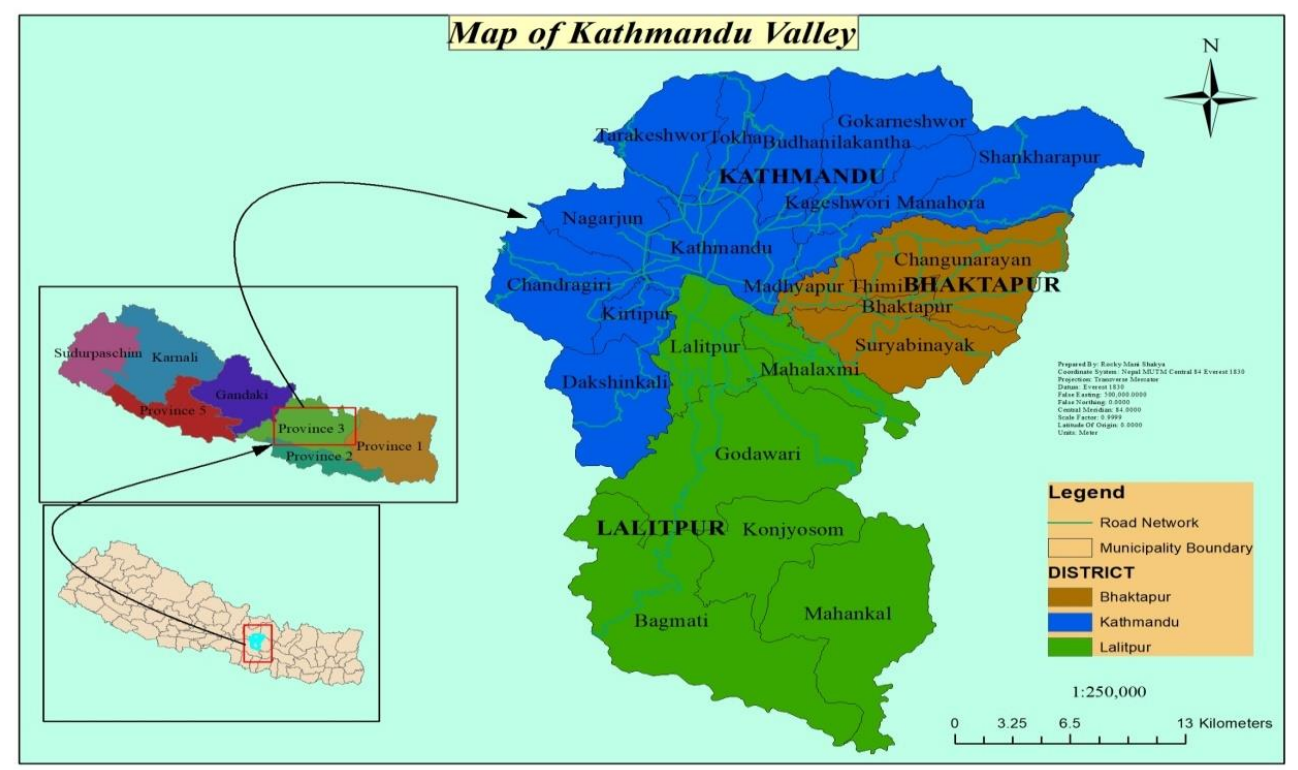




\section{Study Population and Sampling}

The entire population for the $\neg$ purpose of this research would be all those frontline working fathers involved in small business enterprises in Kathmandu valley. They cover different age ranges because it is presumed that people from a diverse age range may employ various strategies in order to deal with work-life balance problems based on their experience and knowledge in different life stages.

Fathers who regularly stay in their small business enterprises are considered as a sample for this study. For selecting the sample, non-probability sampling is used due to the difficulty in assuring all the individuals the equal chance of being selected in the population. Hence the study is based on purposive sampling. Purposive sampling can be very beneficial in situation when research need to reach target sample quickly and sampling, for proportionality is not the main concern (Singh \& Kale, 2007). The sample was obtained by the way of making an informal invitation to the fathers during their leisure time.

Following Panth \& Kafle (2018) and Paudel et al. (2020) the formula was used to work out the sample size for the study is $\mathrm{n}=\mathrm{z} 2 \mathrm{pq} / \mathrm{e} 2$ (Panth \& Kafle, 2018). Where, $\mathrm{n}=$ sample size required for study, value of standard variable at given confidence level (for $95 \%$ confidence level the value of $Z=1.96$ ), $p=$ Prevalence or proportion of an event $50 \%=0.5, \mathrm{p}(1-\mathrm{p})=0.5$, allowable error that can be tolerated (e) $=5 \%$. The total population required for the study is $(1.96) 2 \times 0.5 \times 0.5 /(0.05) 2$ which is $384.16(\approx 384)$. We also considered $5 \%$ non-response error $5 \%$, (i.e384.16*5/100) $=19.21(\approx 20)$. The formula indicates that total $(384+19)=403$ respondents are required for the study. Hence this study is based upon the 405 respondents residing in Kathmandu valley.

\section{Theoretical Model}

The data came from a response of 405 working fathers who are involved in small business enterprises in Kathmandu valley with different approaches to issues of work-family balance for fathers. This study used job strain theory. The main assumption of this theory is that exposure to work places with a specific task profile contributes to the stress related risk (Peter et al., 2002). The theory further suggest that the amount of work-family conflict and stress perceived by an employee will be associated with the amount of control that they feel they have over work as well as family roles (Duxbury \& Higgins, 2016).

A mathematical model has been developed to predict the stress strain curves. This model is based on a phenomenological representation of the shape of the stress-strain curves and the traditional theories for constitutive equations which incorporate the power law.

The stress-strain behavior up to the peak has been modeled using an equation of the form.

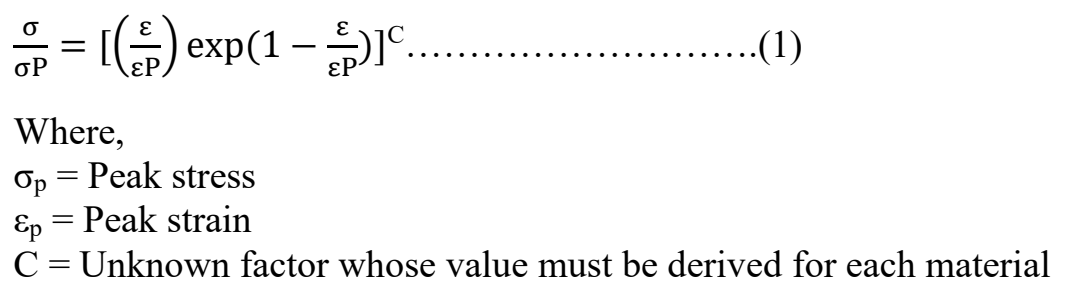

Here in the equation 1, the stress-strain formula is expressed in the terms of peak stress, peak strain, steady state stress and one additional parameter. This analysis has been done for the stress-strain curves under different working conditions (Ebrahimi et al., 2006).

For the empirical analysis of the study, a binary logit model was selected to identify the significant variables that determine the work-life balance among the working fathers in study area. The effect of $X$ on the response probabilities, $P(y=j / x)$ can be estimated by using binary logit model as: 
$P\left(\frac{\mathrm{Yi}}{\mathrm{X}}\right)=F(\mathrm{Zj})=\frac{\mathrm{e} \text { zi }}{1+\mathrm{ezi}}=\frac{1}{1+\mathrm{e}-\mathrm{zi}}$

$(Y i=\mathrm{J} / X i)=F(Z j)=\frac{\mathrm{e} \mathrm{zi}}{1+\mathrm{e} z \mathrm{i}}=\frac{1}{1+\mathrm{e}-\mathrm{zi}}$

$Z i=\beta 0+\beta_{1} X_{1 i}+\ldots+\beta n X_{n i}+\mu_{i}$

The Final equation is:

$Y=\beta 0+\beta 1$ Age $+\beta 2$ Education $+\beta 3$ Level of Education $+\beta 4$ work experience $+\beta 5$ Income + $\beta 6$ Marital Status $+\beta 7$ Child Responsibility $+\beta 8$ Partner Support $+\beta 9$ Elder Dependency + $\beta 10$ Colleague Support+ $\beta 11$ Unfair Criticism $+\beta 12$ Job Resource +

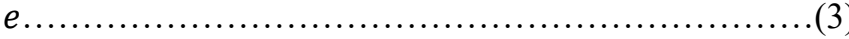

Where, $\mathrm{Y}=$ Dependent variable, $\beta_{0}=$ Constant coefficient, $\beta_{1}-\beta_{12}=$ Coefficient of independent variable and $e=$ Error term.

\section{Data Analysis and Result}

\section{Socio-Demographic Analysis}

Table 1 reveals socio-demographic characteristics of respondents where majority of respondents (32.84\%) were from age group 31-40 years having educational degree up to bachelors' level (29.63\%). Likewise, majority of fathers were found to have received business trainings $(85.19 \%)$. This also shows that majority of working fathers in small-medium enterprises are from young age and all are literate. Majority of them receives business training.

Table 1: Socio-Demographic Characteristics

\begin{tabular}{llll}
\hline \multicolumn{1}{c}{ Title } & \multicolumn{1}{c}{ Number } & Percentage \\
\hline Age & 30 & 7.41 \\
Below 30 & 133 & 32.84 \\
$31-40$ & 109 & 26.91 \\
$41-50$ & 107 & 26.42 \\
$51-60$ & 26 & 6.42 \\
Above 60 & & & \\
Education Level & 25 & 6.17 \\
Illiterate & 6 & 1.48 \\
Primary Level & 24 & 5.92 \\
Lower Secondary Level & 71 & 17.53 \\
Secondary Level & 114 & 28.15 \\
Higher Secondary Level & 120 & 29.63 \\
Bachelor's Degree & 45 & 11.12 \\
Master's Degree & & \\
\hline Business Training & 345 & 85.19 \\
Yes & 60 & 14.81 \\
No & & \\
\hline
\end{tabular}




\section{Factors Affecting Work-life Balance}

There are several factors that might affect work-life balance of working fathers. Majority of working fathers $(48.69 \%)$ stated that unhelpful attitude affects work-life balance of working fathers in small-medium enterprises, followed by high level of stress $(33.33 \%)$. However only $3.27 \%$ thinks unsupportive relationships affects work-life balance. Likewise, $8.82 \%$ and $5.89 \%$ fathers thinks that unrealistic demand and lack of control affects work-life balance respectively.

Figure 2: Factors affecting work-life balance

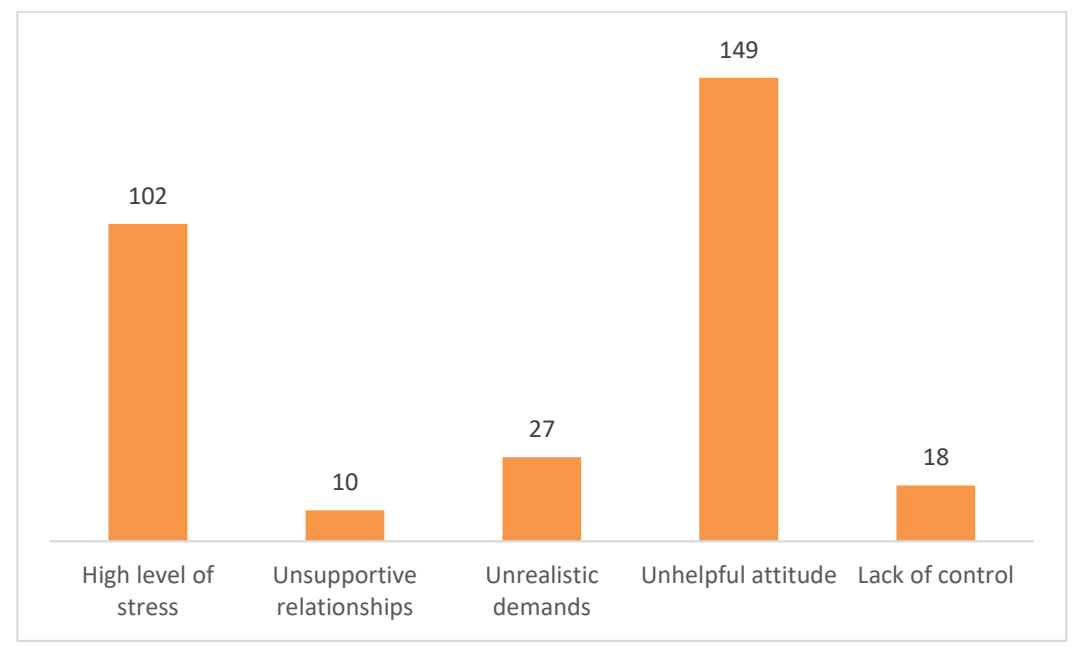

\section{Managerial Implications}

When asked upon what could be the managerial solutions to maintain work-life balance respondents came up with various implications which includes: foster a trusting environment, engage in tea building exercise, allow schedule flexibility, increase transparency, encourage vacations and maintain structural consistency where majority of working fathers believed that maintaining structural consistency would help in maintaining work-life balance to them $(25.92 \%)$.

Figure 3: Managerial Implications

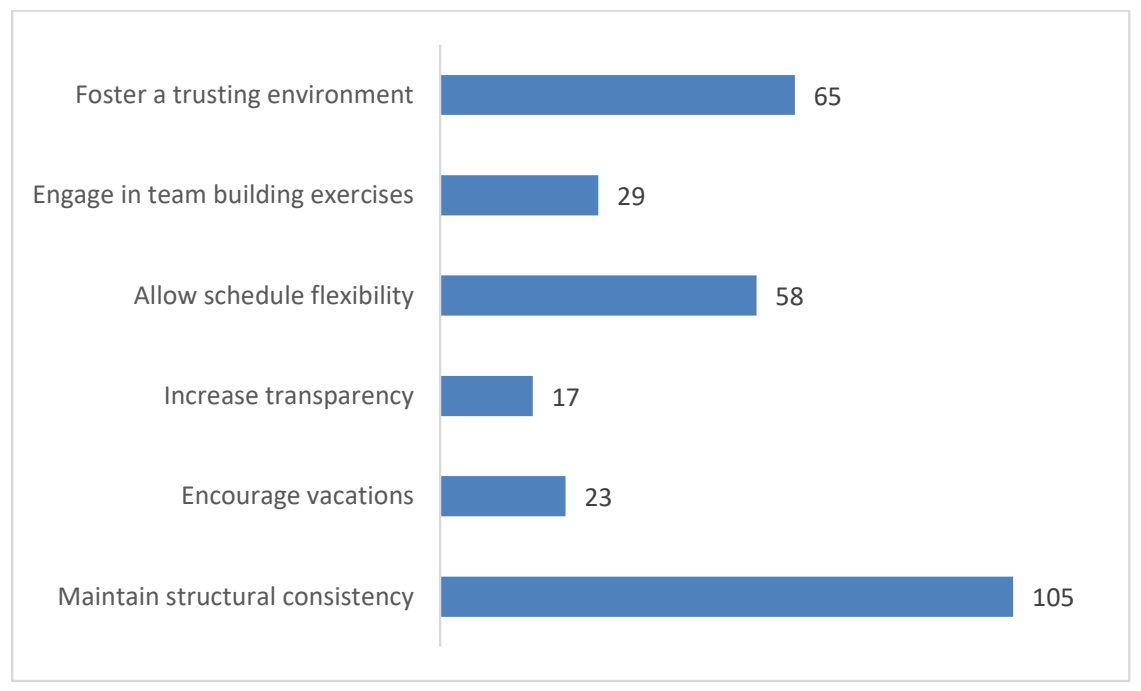


Similarly, $16.05 \%$ believes fostering a trusting environment helps in maintaining work-life balance. Likewise, $14.32 \%$ believed that allowing schedule flexibility would promote work-life balance among them. Some fathers $(7.16 \%)$ also stated that engaging them in team building exercise also helps in work-life balance. $5.67 \%$ and $4.19 \%$ stated that encouraging vacations and increasing transparency would help in maintaining work-life balance respectively.

\section{Logistic Regression}

In this study, logistic regression is performed to predict the work-life balance of working fathers in Kathmandu valley. The Logistic Regression shows the significance between the dependent variable work-life balances with the various independent variables like age, educational level, working experience and so on. This study highlights the significance of work-life balance with the independent variables like age, education level, working experience, business trainings and so on. For understanding whether the data set follows the Ordinary least square (OLS) properties some post estimation test has been performed.

In statistics the robustness tests has been emerged as a response to uncertainty faced by social scientist in specifying the empirical models (Plumper \& Neumayer, 2017). Robust standard error is a technique applied for obtaining unbiased standard errors of OLS under heteroskedasticity or can be understood as the activities conducted when performing the activities like the task and solutions. There is presented the final regression result in table 1:

Table 1: Final Regression Result

\begin{tabular}{|c|c|c|c|}
\hline VARIABLES & (1) & $\begin{array}{c}\text { (2) } \\
\text { Odds ratio }\end{array}$ & $\begin{array}{c}\text { (3) } \\
\text { Marginal effects }\end{array}$ \\
\hline \multicolumn{4}{|l|}{ work_1_balance } \\
\hline \multirow[t]{2}{*}{ Age } & $0.0245^{*}$ & $1.025^{*}$ & $0.00439 *$ \\
\hline & $(0.0148)$ & $(0.0151)$ & $(0.00263)$ \\
\hline \multirow[t]{2}{*}{ edu_level } & $1.311^{* *}$ & $3.710^{* *}$ & $0.235^{* *}$ \\
\hline & $(0.644)$ & $(2.389)$ & $(0.115)$ \\
\hline \multirow[t]{2}{*}{ working_experience } & 0.0748 & 1.078 & 0.0134 \\
\hline & $(0.142)$ & $(0.153)$ & $(0.0255)$ \\
\hline \multirow[t]{2}{*}{ business_trainings } & $0.863 * * *$ & $2.371 * * *$ & $0.155^{* * *}$ \\
\hline & $(0.280)$ & $(0.663)$ & $(0.0479)$ \\
\hline \multirow[t]{2}{*}{ income_level } & $-0.195 *$ & $0.823^{*}$ & $-0.0350 * *$ \\
\hline & $(0.0999)$ & $(0.0821)$ & $(0.0177)$ \\
\hline \multirow[t]{2}{*}{ child_responsibility } & -0.227 & 0.797 & -0.0407 \\
\hline & $(0.274)$ & $(0.219)$ & $(0.0490)$ \\
\hline \multirow[t]{2}{*}{ support_partner } & -0.147 & 0.863 & -0.0264 \\
\hline & $(0.253)$ & $(0.218)$ & $(0.0453)$ \\
\hline \multirow[t]{2}{*}{ colleague_work } & 0.243 & 1.276 & 0.0437 \\
\hline & $(0.244)$ & $(0.311)$ & $(0.0437)$ \\
\hline \multirow[t]{2}{*}{ unfair_criticism } & -0.0692 & 0.933 & -0.0124 \\
\hline & $(0.862)$ & $(0.805)$ & $(0.155)$ \\
\hline \multirow[t]{2}{*}{ job_resources } & 0.0708 & 1.073 & 0.0127 \\
\hline & $(0.736)$ & $(0.790)$ & $(0.132)$ \\
\hline \multirow[t]{2}{*}{ Constant } & $-3.210 * * *$ & $0.0403 * * *$ & \\
\hline & (1.012) & $(0.0408)$ & \\
\hline Observations & 405 & 405 & 405 \\
\hline \multicolumn{4}{|c|}{ Robust standard errors in parentheses } \\
\hline \multicolumn{4}{|c|}{$* * * \mathrm{p}<0.01, * * \mathrm{p}<0.05, * \mathrm{p}<0.1$} \\
\hline
\end{tabular}


The result presented in above table signifies that age, education level, business training and income level are significantly related to work-life balance. In other way it can be said that the probability of work-life balance increases with the education level, business trainings, income level. The first model shows that the odds ratio of the work-life balance increases by 3.710 times when the respondent is educated, 2.371 times when the respondent has taken the business related trainings, 0.823 times when the income level is mentioned. The final regression model also deals with the odds ratio. In the above table of the odds ratio we can clearly see that the dependent variable work-life balance is significant with age i.e. 1.025 , the level of education i.e. 3.710, business training i.e. 2.371 and finally with the income level which is 0.823 .

The results of this study are relevant globally. From the under-developed nation to the developed ones, working fathers who are involved in the small business enterprises have successfully balanced their work-life as well as family life. The attitude of the individuals regarding the work-life balance seem to be positive (Rimi, 2014) in the study conducted in Sweden. As similar to this study, Elliott (2003) which has conducted their research in England clearly showed that more than $68 \%$ of the respondents feel that there are many hurdles in balancing the work-life as well as family life. Hence in that study they have even shown some of the managerial implications to overcome such hurdles and challenges and hence make a proper balance in maintaining work-life and family life. Hence it shows that the result drawn in this result can serve to great roles in order to transform the negative attitude to positive attitude for the effective outcomes.

\section{Conclusion and Recommendation}

This paper provides insights to different dimensions for work-life balance. Therefore this study aims to understand the work-life balance of working fathers as well as analyze the factors determining it. It also aims to suggest the managerial implication for the promoting the work-life balance of working fathers in Kathmandu valley. The objectives of this study are measured through work-life balance index, logistic regression, table, graph and chart. It is concluded from the perception of the sample respondents expressed positively or confident enough to balance their routine work smoothly/comfortably. Due to some economic, family problems, inefficiency, lack of commitment some of the respondents expressed their inability to balance their work and it is also proved that the significant level is high on some of the practices like working hours, flexible stating time, present hours of work, amount of wages earned by the respondents, and training given to the working fathers and mandatory overtime. Hence it is concluded that most of the respondents are satisfied with all the above mentioned practices.

It was evident from the responses that respondents need to spend time with friends and family, have time to exercise, pursue hobbies, as well as performing well in order to achieve their necessary worklife balance. When creating work-life enrichment programs, managers should focus on meeting father's needs for autonomy, competence and relatedness. They need to keep in mind that team bonding activities work well, but that it is crucial for fathers to have time for their families and friends as the need relatedness lacking the most for management consultants. In this 21 st century most of the companies' especially small business enterprises are being aware of the importance of work-life balance (Hobson, 2011). Besides this Hossen et al. (2018) has also mentioned that work-life balance is important as well as vital tool in order to attract as well as retain the sustainable human resources. As similar to our study, Allard et al. (2011) states that age of the working father has played a significant role in maintaining the work-life balance.

Based on the findings of the study, it is suggested that the management of certain selected organizations to plan and take necessary steps to overcome their inhibition and motivate them to enhance their personality as well as their performance by providing stress reducing activities. For instance: rest rooms for relaxation, social meetings, workers participation, and refreshment as and when necessary, recreational facilities, regular breaks, superior and sub-ordinate relations childcare and eldercare, 
periodical counseling for healthy and productive environment. Thus, managing and organizing both work and life of employees systematically and strategically in any public or private sector units have led to enhanced productivity in the long run.

\section{Conflict of Interest}

This article is original and there is no potential conflict of interest with respect to research and publication of this article.

\section{References}

Adams, G. A., King, L. A., \& King, D. W. (1996). Relationships of job and family involvement, family social support, and work-family conflict with job and life satisfaction. Journal of Applied Psychology, 81(4), 411.

Adhikari, D. B., Shakya, B., Devkota, N., Karki, D., Bhandari, U., Parajuli, S., \& Paudel, U. R. (2021). Financial hurdles in small business enterprises in Kathmandu Valley. Modern Economy, 12(6), 1105-1118.

Albertsen, K., Rafnsdóttir, G. L., Grimsmo, A., Tómasson, K., \& Kauppinen, K. (2008). Workhours and work-life balance. Scandinavian Journal of Work, Environment and Health, Supplement, (5), 14-21.

Allard, K., Haas, L.,\& Hwang, C. P. (2011). Family-supportive organizational culture and fathers' experiences of work-family conflict in Sweden. Gender, Work and Organization, 18(2), 141-157.

Borgh, M., Eek, F., Wagman, P., \& Håkansson, C. (2018). Organisational factors and occupational balance in working parents in sweden. Scandinavian Journal of Public Health, 46(3), 409-416.

Carlson, D. S., Kacmar, K. M., \& Williams, L. J. (2000). Construction and initial validation of a multidimensional measure of work-family conflict. Journal of Vocational behavior, 56(2), 249-276.

Chandra, V. (2012). Work-life balance: eastern and western perspectives. International Journal of Human Resource Management, 23(5), 1040-1056.

Duxbury, L., \& Higgins, C. (2016). Employee Assistance Quarterly Interference Between Work and Family, 3(16), $37-41$.

Ebrahimi, R., Zahiri, S. H., \& Najafizadeh, A. (2006). Mathematical modelling of the stress - strain curves of Ti-IF steel at high temperature. Journal of Materials Processing Technology, 171, 301-305.

Elliott, M. (2003). Work and family role strain among university employees work and family role strain among university employees. Journal of Family and Economic Issues, 24(2), 157.

Geurts, S. A., \& Demerouti, E. (2003). Work/non-work interface: A review of theories and findings. The handbook of work and health psychology, 2, 279-312.

Gnawali, A. (2017). Work-family balance and its outcome among female teachers in Nepal. International Journal of Research Studies and Business Management, 4(6), 23-29.

Greenhaus, J. H., \& Beutell, N. J. (1985). Sources of conflict between work and family roles. Academy of management review, 10(1), 76-88.

Grzywacz, J. G. (2000). Reconceptualizing the work-family interface . An Ecological Perspective on the Correlates of Positive and Negative Spillover Between Work and Family. 5(1), 111-126.

Hill, E. J., Hawkins, A. J., Ferris, M., \& Weitzman, M. (2001). Finding an extra day a week: The positive influence of perceived job flexibility on work and family life balance. Family relations, 50(1), 49-58.

Hall, D. T. (1990). Promoting work/family balance: An organization-change approach. Organizational Dynamics, 18(3), 5-18.

Hobson, B. (2011). The agency gap in work-life balance: Applying sens capabilities framework within European contexts. Social Politics, 18(2), 147-167.

Hobson, B., \& Fahlen, S. (2009). Competing scenarios for European fathers: Applying Sen's capabilities and agency framework to work-family balance. Annals of the American Academy of Political and Social Science, 624(1), 214-233.

Hobson, B., Fahlén, S., \& Takács, J. (2011). Agency and capabilities to achieve a work-life balance: A comparison of Sweden and Hungary. Social Politics, 18(2), 168-198.

Hogarth, T., \& Bosworth, D. (2009). Future horizons for work-life balance. Institute for Employment Research, (January), 24-25. 
Hossen, M. M., Begum, M., \& Zhixia, C. (2018). Present status of organizational work-life balance practices in Bangladesh: Employees expectation and organizational arrangements. Journal of Eastern European and Central Asian Research (JEECAR), 5(1), 16.

Ishtiaque, A., Shrestha, M., \& Chhetri, N. (2017). Rapid urban growth in the Kathmandu Valley, Nepal: Monitoring land use land cover dynamics of a himalayan city with landsat imageries. Environments, 4(4), 72.

Karambayya, R., \& Reilly, A. H. (1992). Dual earner couples: Attitudes and actions in restructuring work for family. Journal of Organizational Behavior, 13(6), 585-601.

Maslach, C., Schaufeli, W. B., \& Leiter, M. P. (2001). Job burnout. Annual review of psychology, 52(1), 397-422.

McEnhill, L., \& Steadman, K. (2015). This won't hurt a bit: supporting small business to be healthy, wealthy and wise.

Mills, M. J., \& Grotto, A. R. (2017). Who can have it all and how?: An empirical examination of gender and worklife considerations among senior executives. Gender in Management, 32(2), 82-97.

Naithani, P. (2010). Overview of work-life balance discourse and its relevance in current economic scenario. Asian Social Science, 6(6), 148-155.

Neugarten, B. L., \& Datan, N. (1973). Sociological perspectives on the life cycle. In Life-span developmental psychology (pp. 53-69). Academic Press.

Panth, A., \& Kafle, P. (2018). Maternal satisfaction on delivery service among postnatal mothers in a government hospital, Mid-Western Nepal. Obstetrics and gynecology international, 29(4), 165-190

Pathak, R. R. (2015). Work life balance in Nepalese commercial banks. Journal of Business and Social Sciences, $116-125$.

Peter, R., Alfredsson, L., Hammar, N., Siegrist, J., Theorell, T., \& Westerholm, P. (2002, September). Job strain, effort-reward imbalance, and coronary risk factors - complementary job stress models in risk estimation?. In International Congress Series (Vol. 1241, pp. 165-171). Elsevier.

Plümper, T., \& Neumayer, E. (2017). Robustness tests and statistical inference. London: Department of Geography, London School of Economics.

Pocock, B. (2005). Work-life 'balance' in Australia: Limited progress, dim prospects Barbara Pocock. Asia Pacific Journal of Human Resources, 43(2), 198-209.

Quesenberry, J. L., \& Trauth, E. M. (2005). The role of ubiquitous computing in maintaining work-life balance: Perspectives from women in the information technology workforce. In Designing ubiquitous information environments: Socio-technical issues and challenges (pp. 43-55). Springer, Boston, MA.

Ravalier, J. M., Wegrzynek, P., \& Lawton, S. (2016). Systematic review: complementary therapies and employee well-being. Occupational Medicine, 66(6), 428-436.

Rimi, N. N. (2014). Achieving balance in work-family conflict through the influences of family supportive HRM : A conceptual framework for the organizations of Bangladesh. 1(3), 80-99.

Ritvo, S. (1971). Late adolescence: Developmental and clinical considerations. The Psychoanalytic Study of the Child, 26(1), 241-263.

Rusten, N. F., Peterson, E. R., Underwood, L., Verbiest, M. E. A., Waldie, K. E., Berry, S., Morton, S. M. B. (2019). Psychological distress among resident and nonresident fathers: Findings from New Zealand's who are today's dads? Journal of Family Issues, 40(3), 293-314.

Salzmann-Erikson, M. (2017). Work life and family life collide: Online support for new fathers. Workplace Health and Safety, 65(6), 248-252.

Singh, H., \& Kale, P. (2007). Building firm capabilities through learning: The role of the alliance learning process in alliance capability and firm-level alliance success. Strategic Management Journal, (28), 981-1000.

Smithson, J., \& Stokoe, E. H. (2005). Discourses of work-life balance: Negotiating "Genderblind" terms in organizations. Gender, Work and Organization, 12(2), 147-168.

Tang, N., \& Cousins, C. (2005). Working time, gender and family: an East-West European comparison. Gender, Work \& Organization, 12(6), 527-550.

Williams, J. C., Berdahl, J. L., \&Vandello, J. A. (2016). Beyond work-life "Integration." Annual Review of Psychology, 67(1), 515-539.

Zedeck, S., \& Mosier, K. L. (1990). Work in the family and employing organization. American Psychologist, $45(2), 240-251$. 